Çukurova Üniversitesi Mühendislik Mimarlık Fakültesi Dergisi, 32(3), ss. 187-195, Eylül 2017

\title{
Horzum Yaylasındaki Pb-Zn Madeninin Atıkları ve Drenaj Sularındaki Arsenik ve Ağır Metallerin İncelenmesi
}

\author{
Mesut BAŞIBÜYÜK ${ }^{1}$, Başak Deniz ERGÜN ${ }^{* 1}$ \\ ${ }^{1}$ Çukurova Üniversitesi, Mühendislik Mimarlık Fakültesi, Çevre Mühendisliği Bölümü, Adana
}

Geliş tarihi: 08.06.2017 Kabul tarihi: 25.09.2017

Öz

Maden atıkları ve drenaj suları, ağır metal ve arsenik içerikleri dolayısıyla çevre ve halk sağlı̆̆ı açısından tehlike arz etmektedir. Maden drenaj sularının nehirlere ulaşması ile yüzey sularında taşınabileceği gibi, sızma ve süzülme ile yeraltı sularına da karışabilir. Adana'nın Kozan ilçesine bağlı Horzum Yaylası'nda mevcut bulunan işletimi durmuş bir $\mathrm{Pb}-\mathrm{Zn}$ madeni civarında yapılan analizlerde yüksek miktarlarda ağır metal iyonuna rastlanmıştır. Maden atıklarına kireç eklenmesi, ağır metallerin ve özellikle de arseniğin alıcı ortamlara karışmasını engelleyici bir yöntem olarak kullanılmaktadır. Analiz sonucunda tespit edilen konsantrasyonlar, jeokimyasal olarak mevcut koşullarda bir değişikliğin oluşmaya başladığını dolayısıyla sudaki ağır metal ve arsenik iyonu konsantrasyonlarının artabileceğine yönelik işaretler vermektedir.

Anahtar Kelimeler: Ağır metal ekstraksiyonu, Toprak kirliliği, Kohezyon suyu, Terkedilmiş maden ocağ1

\section{Investigation of Arsenic and Heavy Metals in Mine Wastes and Drainage Waters at a $\mathrm{Pb}-\mathrm{Zn}$ Mine at Horzum Plateau}

\begin{abstract}
In this Mining is one of the most developed sectors in Turkish industry. Mining wastes and draiange waters are a big concern in terms of environment and public health due to their heavy metals and arsenic content. Mine drainage waters can be transported to surface waters by rivers as well as to groundwater by infiltration and percolation. Mine waste samples and drainage water samples are collected at a currently non-operating $\mathrm{Pb}-\mathrm{Zn}$ mine at Horzum Plateau in Kozan, Adana. Analysis resuted high concentrations of heavy metal in the vicinity of mining area. Lime addition have been used as a preventetive method for metals and arsenic dissolution from the mine wastes at the mine. However, the concentrations determined suggests some sort of geochemical change in the present conditions of the mine wastes and drainage waters which could result in higher metals and arsenic concentrations in receiving waters.
\end{abstract}

Keywords: Heavy metal extraction, Soil contamination, Pore water, Abondoned mine site

\footnotetext{
*Sorumlu yazar (Corresponding author): Mesut BAŞIBÜYÜK, basibuyuk@cu.edu.tr
} 


\section{GíRiş}

Türkiye madenler bakımından zengin bir ülkedir, yataklarında pek çok mühim cevheri bulundurmaktadır. Ülkemizde madencilik, sanayinin gelişmiş kollarından birisidir. Madencilikle uğraşan kuruluşların ülke ekonomisine ve bölge insanlarına başlıca iki önemli etkisi bulunmaktadır. Olumlu etkileri arasında, bölgede istihdam yaratması, işsizliği azaltması ve sanayi dallarını geliştirmesi gibi etkiler sayılabilirken; olumsuz etkileri arasında, yer altı ve yer üstü maden işletmelerinin arazi yapısını bozduğu, ekolojik dengeye zarar verdiği (kontrolsüz maden atıkları dolayısıyla tarım alanlarına, akarsulara ve canlılara geri dönüşü olmayan zararlar vermektedir) ve turistik bölgelerde doğal ve tarihi yapıyı bozduğu söylenebilmektedir.

Madenler, arkalarında bozunmuş bir arazi, kirlenmiş su ve zarar görmüş komüniteler bırakan yapılardır. Madencilikte altın, gümüş ve bakır gibi metallerin çıkarımı, çevreyi inanılmaz bir şekilde etkilemektedir; yüzey ve yeraltı suları, sucul yaşam, vejetasyon, toprak, hava, vahşi yaşam ve insan sağlığı üzerine etkileri bulunmaktadır. Maden faaliyetleri çevreye, cevher çıkarma işlemleri sırasında öğütücüler ve kırıcılar ile kaynaktan kimi zaman yüzlerce kilometre öteye kadar taşınabilen, ağır metal döküntüleri ve toksik bileşenler salmaktadırlar. Madenlerin çevreye uzun vadede pek çok etkisi bulunmaktadır. Madencilik faaliyetleri sonucu açığa çıkan ağır metaller taşınabilir özellikleri ile etrafa yayılmakta ve uzun yıllar boyunca doğada kalabilmektedir. Böylece madenler, ağır metal kirliliğine sebep olmaktadırlar. Maden şirketleri cevherden hedef minerali ayırmak için siyanür ya da sülfürik asit gibi kimyasalların kullanmaktadırlar, bu tip kimyasallar da doğa ve vahşi yaşam için oldukça toksiktir. Bir çay kaşı̆̆ı kadar \%2'lik bir siyanür çözeltisi insanı öldürmeye yetebilir. Kuş ve memeliler litrede miligram (ppm) konsantrasyonlarında ölümle sonuçlanırken, balık ve diğer sucul organizmalar litrede mikrogram seviyesindeki konsantrasyonlarda ölebilmektedirler. Madencilik endüstrisi her yıl 180.000 ton gibi büyük miktarlarda siyanür kullanmaktadır ve sorumsuzca kullanımın sonucu olarak pek çok doğa felaketi görülebilmektedir

Madencilik, Türkiye'nin gelişmiş sanayi kollarından birisidir. Aynı zamanda çevre için en önemli ağır metal kaynağıdır. Madencilik faaliyetleriyle, çok geniş toprak alanları kirlenebilmektedir. Topraklardaki kirleticiler, üzerinde yetişen bitkilerin bünyelerine, civardaki yüzey sularına dolayısıyla ortamda yaşayan hayvanlara ve oradan da bu bitki ve hayvanların besin olarak tüketilmesiyle insana geçmektedir. Türkiye kurşun rezervi 140 milyon ton civarındadır. Türkiye'de ise toplamda 3.250 .000 ton kurşun rezervi bulunmaktadır. Türkiye'de çinko metali rezervi 5471338 ton olup araştırma alanımız olan Horzum Bölgesi'ndeki madenin çinko-kurşun rezervi görünür 50 bin ton, muhtemel 100 bin ton ve toplam 250 bin tondur. Ortalama metal içeriği ise \%15-40 Pb, \%30 Zn'dir [1]. Yaklaşık 240 tanesi aktif, çok büyük bir kısmı on yıllardır kapalı şekilde olan çinko-kurşun madenleri dünya genelinde yaygın madenler arasındadır [2].

\section{2. ÖNCEKİ ÇALIŞMALAR}

Önceki çalışmalar, doğadaki ağır metal kirliliğinin genellikle maden ve metalurjik faaliyetlerden kaynaklandığını göstermektedir [3-8]. Ağır metaller çoğunlukla çevreye rüzgar ya da su yoluyla dağılmışlardır. Son zamanlardaki su kıtlığı, nehirlerde meydana gelen kuraklık ve su kirliliği nedeniyle büyük bir sorun haline gelmiştir. Ağır metallere uzun süreli maruz kalma merkezi ve periferik sinir sistemi ve dolaşımı etkileyen kanserojen olabilir. Yüksek ağır metal konsantrasyonları insanda olumsuz sağlık etkilerine sebep olabilir [9].

Kum, çakıl gibi gevşek sedimentlerden çıkarılan kohezyon sularında yüksek miktarlarda As konsantrasyonuna rastlanmıştır, Widerlund ve Ingri (1995) Kuzey İsveç'de Kalix Nehri'nde 1,3-166 $\mu \mathrm{g} / 1$ aralığında As oranı rapor etmişlerdir [10]. Yan ve arkadaşları (2000) Kanada'daki Saskatchewan'daki kil sedimentlerinin kohezyon suyunda 3,2-99 $\mu \mathrm{g} / 1$ aralığında As konsantrasyonu bulmuşlardır [11]. 
Maden etrafındaki toprak ve bitkilerdeki arsenik kirliliği üzerine yapılan çalışmalar mevcuttur.

Bech ve arkadaşları, 1997'de Kuzey Peru'daki bakır madeni çevresindeki bitki örtüsü ve toprağı arsenik ve ağır metal kirliliği yönünden araştırmışlardır. Bitki analizleri sonucunda numune alınan pek çok alanda, yapraklarda alışılmışın dışında yüksek miktarlarda $\mathrm{Fe}$ ve $\mathrm{Al}$ elementleri saptanmıştır. Maden civarındaki farklı alanlardan toplanan toprak örneklerindeki $\mathrm{As}, \mathrm{Cd}$, $\mathrm{Zn}, \mathrm{Cu}, \mathrm{Pb}, \mathrm{Mn}$ konsantrasyonları en fazla sirasiyla 7670, 499, 772, 5270, 285, $965 \mathrm{mg} / \mathrm{kg}$ olmakla birlikte Fe ve Al konsantrasyonları \%5,95 ile 9,14 olarak bulunmuşlardır [12].

Jung ve arkadaşları, Kore'de Au-Ag-Pb-Zn madeni olan Daduk Madeni ve çevresinin ağır metal kirliliğini araştırmışlardır. Toprak örneklerinde de yapmış oldukları ağır metal tayinleri sonucu, $\mathrm{Cd}$, $\mathrm{Cu}, \mathrm{Pb}, \mathrm{Zn}$ kirlenmesi bulunmuş ve bunların konsantrasyonlarının sirasıyla 8,$57 ; 481 ; 4450$ ve $753 \mathrm{mg} / \mathrm{kg}$ olduğu tespit edilmiştir [13].

Rotkittikhun ve arkadaşlarının 2005 yılında Tayland Bo Ngam Madeni'nde yapmış oldukları çalışmada, toprak numuneleri, bitki çevresinden; yüzeyden $0-10 \mathrm{~cm}$ ve yüzey altı $10-40 \mathrm{~cm}$ olmak üzere toplanmış ve kurşun konsantrasyonları tayin edilmiştir. En yüksek $\mathrm{Pb}$, yüzey toprakta 142400 ve yüzey altı toprakta $120850 \mathrm{mg} / \mathrm{kg}$ olmak üzere cevher zenginleştirme tesis alanında tespit edilmiştir. Maden civarında en düşük $\mathrm{Pb}$ konsantrasyonu ise yüzey toprak numunesinde 325 , yüzey altı numunede $86 \mathrm{mg} / \mathrm{kg}$ doğal gölet alanında bulunmuştur [14].

Madzin ve ark, Malezya Selangorda, Betari Jaya bölgesinde terkedilmiş maden alanları civarında ağır metal üzerine çalışma gerçekleştirmişlerdir. Araştırma sonucunda terkedilmiş maden bölgesindeki sulardan alınan örneklerdeki ağır metal miktarlarının, Sağlık Bakanlığı'nın hamsu için bildirmiş olduğu kalite standartlarının altında olduğunu tespit etmişlerdir. $\mathrm{pH}$ değişimi metal çözünürlüğünü etkilediğinden su ve sedimentlerdeki ağır metal miktarları arasında pH'a göre ters bir ilişski olduğunu bildirmişlerdir [9].
Fas, Zaida'da 1972 ila 1985 yılları arasında işletilmiş kurşun madeninde bölgedeki toprakların ağır metal kirlilikleri araştırılmıştır. Çizelge 1'de toprak numunelerinin ortalama ve maksimum ağır metal konsantrasyonları verilmiştir [15].

Çizelge 1. Toprak numunelerinin ağır metal konsantrasyonları $(\mathrm{mg} / \mathrm{kg})$

\begin{tabular}{|l|c|c|c|c|}
\hline & $\mathrm{Cd}$ & $\mathrm{Co}$ & $\mathrm{Cr}$ & $\mathrm{Cu}$ \\
\hline Ortalama & 0,99 & 5,42 & 47,35 & 15,31 \\
\hline Maksimum & 3,00 & 20,40 & 777,20 & 77,2 \\
\hline & $\mathrm{Ni}$ & $\mathrm{Zn}$ & $\mathrm{Pb}$ & \\
\hline Ortalama & 13,12 & 48,50 & 94,49 & \\
\hline Maksimum & 48,90 & 206,0 & 830,95 & \\
\hline
\end{tabular}

Gutierrez ve arkadaşlarının 2016 yılında terkedilmiş $\mathrm{Pb}-\mathrm{Zn}$ madeninde yaptıkları araştırmada, toprak ve sedimentlerdeki ağır metal konsantrasyonlarının çoğunlukla $1000 \mathrm{mg} / \mathrm{kg} \mathrm{Zn}$, $100 \mathrm{mg} / \mathrm{kg} \mathrm{Pb}$ ve $10 \mathrm{mg} / \mathrm{kg} \mathrm{Cd}$ siralamasiyla olduğu ve mobilitelerinin ise $\mathrm{Cd}>\mathrm{Zn}>\mathrm{Pb}$ şeklinde olduğu raporlanmıştır [2].

Monterroso ve ekibi, İspanya'da $\mathrm{Pb}-\mathrm{Zn}$ maden topraklarında ağır metal yayılımını araştırmışlardır. Maden topraklarının yüksek heterojenlikte olduğu ve ana olarak $\mathrm{Cd}, \mathrm{Hg}, \mathrm{Pb}$ ve $\mathrm{Zn}$ metal içerdiklerini bulmuşlardır. Toplam ağır metal konsantrasyonları ise 2-95 $\mathrm{mg} / \mathrm{kg} \mathrm{Cd}$, 0,2-24,8 $\mathrm{mg} / \mathrm{kg} \mathrm{Hg}$, 46-6100 $\mathrm{mg} / \mathrm{kg} \mathrm{Pb}$ ve $340-52000 \mathrm{mg} / \mathrm{kg}$ Zn olarak raporlanmıştır [16].

\section{MATERYAL VE METOT}

\subsection{Materyal}

Araştırma alanı olan işletimi durmuş çinko-kurşun madeni Horzum yaylasında yer alıp, Adana'nın Kozan ilçesine bağlıdır. 35 50'52.66" doğu boylamı ile $37^{\circ} 38^{\prime} 16.53$ ' kuzey enlemi arasında yer almaktadır. Kozan, Adana şehir merkezine yaklaşık $70 \mathrm{~km}$ uzaklıkta bulunmaktadır. Maden atık kümeleri hem işletimde olduğu dönemde, hem 
de her hangi bir zamanda ihtiyaç duyulduğunda kireç eklenerek nötralize edilmektedir. $\mathrm{Bu}$ uygulamayla ağır metallerin hidroksit formunda çöktürülmesi sağlanmakta ve böylece alıcı ortamlara ulaşması engellenmektedir.
Horzum Yaylası bölgesinde işletimi durmuş çinkokurşun madeninden, Şekil 1'de gösterildiği gibi maden atık kümesinden ve drenaj suyundan seçilen noktalardan toprak, sediment ve su numuneleri toplanmıştır.

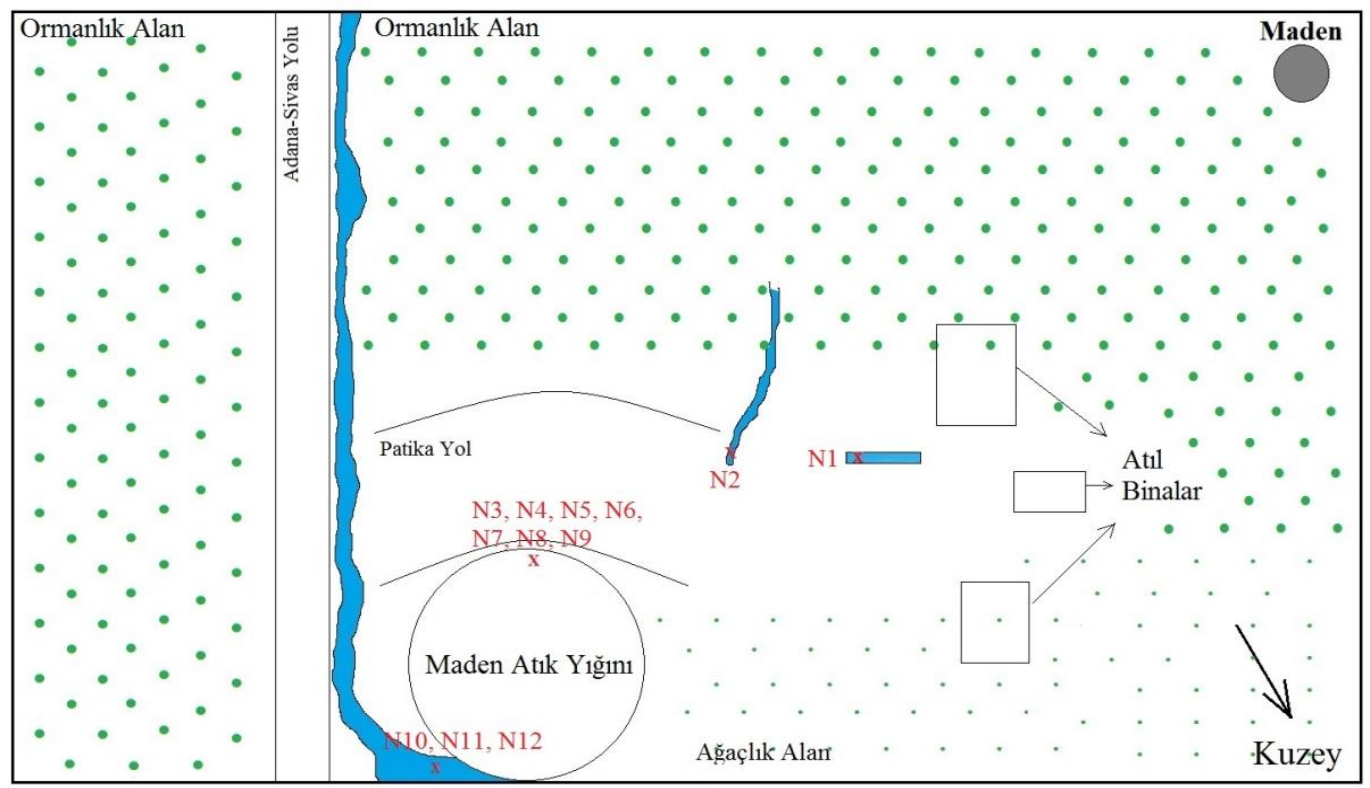

Şekil 1. Numune alım noktaları

Çizelge 2. Numune adlandırmaları

\begin{tabular}{|c|l|}
\hline Kodu & Numune Uzun Tanımı \\
\hline N1 & Maden drenaj suyu \\
\hline N2 & $\begin{array}{l}\text { Maden drenajı sediment numunesi/kohezyon } \\
\text { suyu }\end{array}$ \\
\hline N3 & $\begin{array}{l}\text { Maden drenaj atık kümesinden alınan Carex } \\
\text { bitkisinin toprağ1 }\end{array}$ \\
\hline N4 & $\begin{array}{l}\text { Maden drenaj atık kümesinin tepesinden } \\
\text { alınan kırmızı toprak }\end{array}$ \\
\hline N5 & Toprak yığını \\
\hline N6 & Atık kümesinden alınan 1. bitki toprağ1 \\
\hline N7 & $\begin{array}{l}\text { Maden drenaj atık kümesinden alınan ikinci } \\
\text { bitki toprağ1 }\end{array}$ \\
\hline N8 & Kaya numunesi \\
\hline N9 & Atık kümesinin tepesindeki sert toprak \\
\hline N10 & $\begin{array}{l}\text { Atık kümesinin drenaj kanalından alınan } \\
\text { toprak }\end{array}$ \\
\hline N11 & $\begin{array}{l}\text { Maden atık drenajının aktığ1 kanal sedimenti } \\
\text { /kohezyon suyu }\end{array}$ \\
\hline N12 & Maden atık kümesi drenaj suyu \\
\hline
\end{tabular}

\subsection{Metot}

Tespit edilen noktalardan numuneler alınırken yüzeydeki taş, çakıl, bitki örtüsü v.s. temizlendikten sonra toprak numuneleri $0-15 \mathrm{~cm}$ derinlikten toplanmış [17] ve toprak numune kaplarına koyularak Çukurova Üniversitesi Çevre Mühendisliği Kimya Laboratuvarına getirilmişlerdir. Sediment ve toprak numuneleri oda sıcaklığında kurutulmaya bırakılmış ve $2 \mathrm{~mm}$ (10 mesh) boyutlu elekten geçirilerek ekstraksiyona hazır hale getirilmişlerdir. Laboratuvara getirilen sıvı örnekler, saklama koşulları için uygun $\mathrm{pH}$ seviyelerine düşürülerek, $+4 \mathrm{C}^{\circ}$ de muhafaza edilmişlerdir. Kohezyon suyu numuneleri, sediment numunelerinin $5000 \mathrm{rpm}$ devirde 5 dakikalık santrifüj işlemi sonrası elde edilmişlerdir.

Toprak ve sediment numunelerinin ICP-OES'deki ağır metal tayini için yapılan ön hazırlık işlemidir. 
Bunun için BERGHOF marka MWS-2 model mikrodalga fırın kullanılmış ve parçalama işlemi EPA 3051A'ya göre yapılmıştır [18].

Mikrodalga haznelerine alınan yaklaşık $0,45 \mathrm{~g}$ toprak ve sediment numunelerinin her birinin üzerine EPA 3051A'ya uygun olarak $3 \mathrm{ml}$ $\% 30 \mathrm{HCl}$ ve $9 \mathrm{ml} \% 70 \quad \mathrm{HNO}_{3}$ eklenerek mikrodalgaya yerleştirilmiş ve mikrodalgaya önceden yüklenmiş EPA 3051A'ya göre uygun basınç, sıcaklık, güç ve diğer parametre ayarlarının kayıtlı olduğu program (P2), teknik föy yardımıyla seçilmiştir [19]. Parçalama işlemlerinden çıkan çözelti ise Whatman GF/C filtre kağıdı ile filtre edilerek 100 ml'ye saf su ile tamamlanmış ve ICP-OES'de ağır metal analiz tarihine kadar $4{ }^{\circ} \mathrm{C}$ 'de HDPL-plastik şişelerde saklanmışlardır.

\section{SONUÇLAR VE TARTIŞMA}

US EPA Sediment Kalite K1lavuzu sedimentlerde arsenik, krom, bakır, nikel, kurşun ve çinko konsantrasyonları sirasiyla $8,75,50,50,60$ ve $200 \mathrm{mg} / \mathrm{kg}$ 'ın üzerinde olan sınıfı "çok kirli" olarak tanımlamıştır [19]. Araştırma alanındaki sediment ve toprak numuneleri arsenik konsantrasyonu $30-3320 \quad \mathrm{mg} / \mathrm{kg}$ arasinda değişmekte olup alınan numunelerin ortalama arsenik konsantrasyonu $630 \mathrm{mg} / \mathrm{kg}$ olarak tespit edilmiştir. Fas, Zaida'da 1972 ila 1985 yılları arasında işletilmiş kurşun madeninde bölgedeki toprakların ağır metal kirlilikleri araştırılmıştır. $\mathrm{Cd}$, $\mathrm{Co}, \mathrm{Cr}, \mathrm{Cu}, \mathrm{Ni}, \mathrm{Zn}$ ve $\mathrm{Pb}$ konsantrasyonları belirlenen araştırmada sırasıyla 0,99; 5,42; 47,35; 15,$31 ; 13,12 ; 48,50 ; 94,49 \mathrm{mg} / \mathrm{kg}$ ortalama değerler bulunmuştur (Çizelge 1) [15].

Çizelge 3. Topraktaki ağır metal sınır değerleri [20].

\begin{tabular}{|l|c|c|c|}
\hline \multicolumn{1}{|c|}{ Metal } & Birim & $\begin{array}{c}\mathrm{pH} \mathrm{5-6} \\
\text { firın kuru } \\
\text { toprak }\end{array}$ & $\begin{array}{c}\mathrm{pH}>6 \text { firın } \\
\text { kuru toprak }\end{array}$ \\
\hline Kadmiyum & $\mathrm{mg} / \mathrm{kg}$ & 1 & 3 \\
\hline Krom & $\mathrm{mg} / \mathrm{kg}$ & 100 & 100 \\
\hline Bakır & $\mathrm{mg} / \mathrm{kg}$ & 50 & 140 \\
\hline Kurşun & $\mathrm{mg} / \mathrm{kg}$ & 50 & 300 \\
\hline Civa & $\mathrm{mg} / \mathrm{kg}$ & 1 & 1,5 \\
\hline Çinko & $\mathrm{mg} / \mathrm{kg}$ & 150 & 300 \\
\hline Nikel & $\mathrm{mg} / \mathrm{kg}$ & 30 & 75 \\
\hline
\end{tabular}

Çizelge 4. U.S. EPA sediment kalite k1lavuzu (mg/kg kuru ağırlık) [19]

\begin{tabular}{|c|c|c|c|}
\hline $\begin{array}{c}\text { U.S. EPA } \\
\text { Toksisite } \\
\text { Sınıflandırmas1 }\end{array}$ & $\begin{array}{c}\text { Kirli } \\
\text { Olmayan }\end{array}$ & $\begin{array}{c}\text { Kismen } \\
\text { Kirlenmiş }\end{array}$ & $\begin{array}{c}\text { Çok } \\
\text { Kirli }\end{array}$ \\
\hline $\mathrm{Pb}$ & $<40$ & $40-60$ & $>60$ \\
\hline $\mathrm{As}$ & $<3$ & $3-8$ & $>8$ \\
\hline $\mathrm{Cd}$ & - & - & $>6$ \\
\hline $\mathrm{Cr}$ & $<25$ & $25-75$ & $>75$ \\
\hline $\mathrm{Cu}$ & $<25$ & $25-50$ & $>50$ \\
\hline $\mathrm{Ni}$ & $<20$ & $20-50$ & $>50$ \\
\hline $\mathrm{Zn}$ & $<90$ & $90-120$ & $>200$ \\
\hline
\end{tabular}

Maden atık kümesi ve maden çevresinden toplanan toprak ve sediment örneklerinin içeriğinde yer alan ağır metal konsantrasyonları Çizelge 5'de; maden ve maden atık kümesi drenaj suları ile sediment 6numunelerinin santrifüjlenmesi sonucu elde edilen kohezyon suyu ağır metal konsantrasyonları Çizelge 6'da verilmektedir.

Çizelge 5. Toprak ve sediment numunelerinin ağır metal konsantrasyonları

\begin{tabular}{|c|c|c|c|c|c|}
\hline Numune (g/kg) & $\mathbf{A l}$ & $\mathbf{A s}$ & $\mathbf{C d}$ & $\mathbf{C r}$ & $\mathbf{C u}$ \\
\hline N2 & 24,38 & 0,024 & 0,013 & 0,032 & 0,1 \\
\hline N3 & 18,5 & 0,03 & 0,008 & 0,024 & 0,095 \\
\hline N4 & 5,86 & 3,32 & 0,079 & 0,099 & 0,545 \\
\hline N5 & 0,1 & 0,17 & 0,005 & 0,007 & 0,108 \\
\hline N6 & 0,19 & 0,14 & 0,0014 & 0,021 & 0,09 \\
\hline N7 & 0,6 & 0,25 & 0,015 & 0,027 & 0,221 \\
\hline N8 & 3,233 & 1,524 & 0,193 & 0,042 & 2,6 \\
\hline N9 & 0,22 & 0,17 & ND & 0,027 & 0,091 \\
\hline N10 & ND & 0,24 & ND & 0,024 & 0,122 \\
\hline N11 & 7,39 & 0,45 & 0,01 & 0,034 & 0,205 \\
\hline Ortalama & 6,72 & 0,63 & 0,04 & 0,03 & 0,42 \\
\hline Numune (g/kg) & Fe & Ni & Mn & Pb & Zn \\
\hline N2 & 41,35 & 0,043 & 0,665 & 0,032 & 5,48 \\
\hline N3 & 31,15 & 0,03 & 0,641 & 0,34 & 3,73 \\
\hline N4 & 297,89 & 0,045 & 0,175 & 79,67 & 32,12 \\
\hline N5 & 52,43 & ND* & 1,97 & 0,36 & 2,91 \\
\hline N6 & 51,5 & ND & 1,443 & 1,15 & 2,18 \\
\hline N7 & 63,97 & 0,003 & 1,85 & 0,7 & 9,01 \\
\hline N8 & 309,33 & ND* & 0,8 & 0,313 & 45,04 \\
\hline N9 & 70,55 & ND* & 0,19 & 0,74 & 2,34 \\
\hline N10 & 277,02 & ND & 0,119 & 0,56 & 2,57 \\
\hline N11 & 120,76 & 0,01 & 0,562 & 1,63 & 9,84 \\
\hline Ortalama & 131,60 & 0,03 & 0,84 & 8,55 & 11,52 \\
\hline ND Cina & 167 & deg & & \\
\hline
\end{tabular}

*ND=Cihaz, ölçüm değerinin altında sonuçlar elde edilmiştir. 
Çizelge 6. Su ve kohezyon suyu numuneleri ağır metal konsantrasyonları

\begin{tabular}{|c|c|c|c|c|c|}
\hline Numune (mg/L) & Al & As & Cd & Cr & Cu \\
\hline N1 & ND & ND & 0,006 & 0,009 & ND \\
\hline N2 & 7,05 & ND & 0,34 & 0,12 & 0,08 \\
\hline N11 & 1,62 & 0,075 & 0,011 & 0,019 & 0,061 \\
\hline N12 & ND & ND & 0,002 & 0,009 & ND \\
\hline Ortalama & 4,34 & 0,08 & 0,09 & 0,04 & 0,07 \\
\hline Numune (mg/L) & Fe & Mn & Ni & Pb & Zn \\
\hline N1 & 0,07 & 0,01 & ND & ND & 1,75 \\
\hline N2 & 2,73 & 1,01 & 0,08 & 3,43 & 7,2 \\
\hline N11 & 71,87 & 2,71 & 0,008 & 0,83 & 3,54 \\
\hline N12 & 7,12 & 2,023 & ND & ND & 1,18 \\
\hline Ortalama & 20,45 & 1,44 & 0,04 & 2,13 & 3,42 \\
\hline
\end{tabular}

*ND=Cihaz, ölçüm değerinin altında sonuçlar elde edilmiştir.

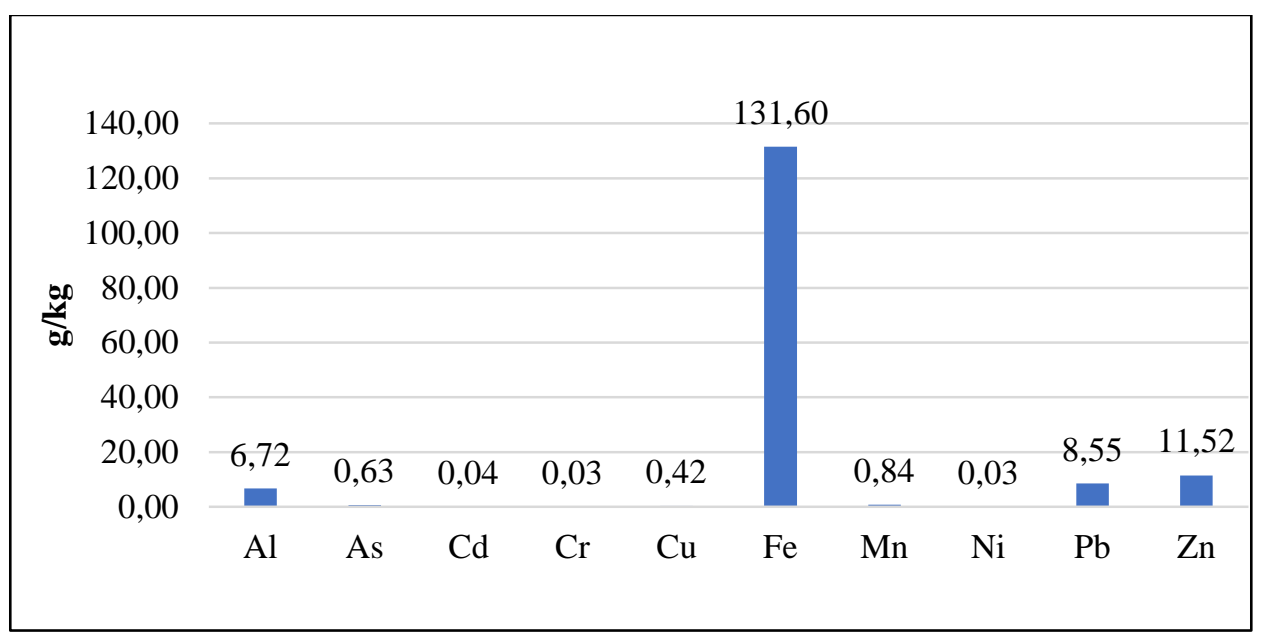

Şekil 2. Toprak ve sediment numunelerinin ortalama metal içerikleri

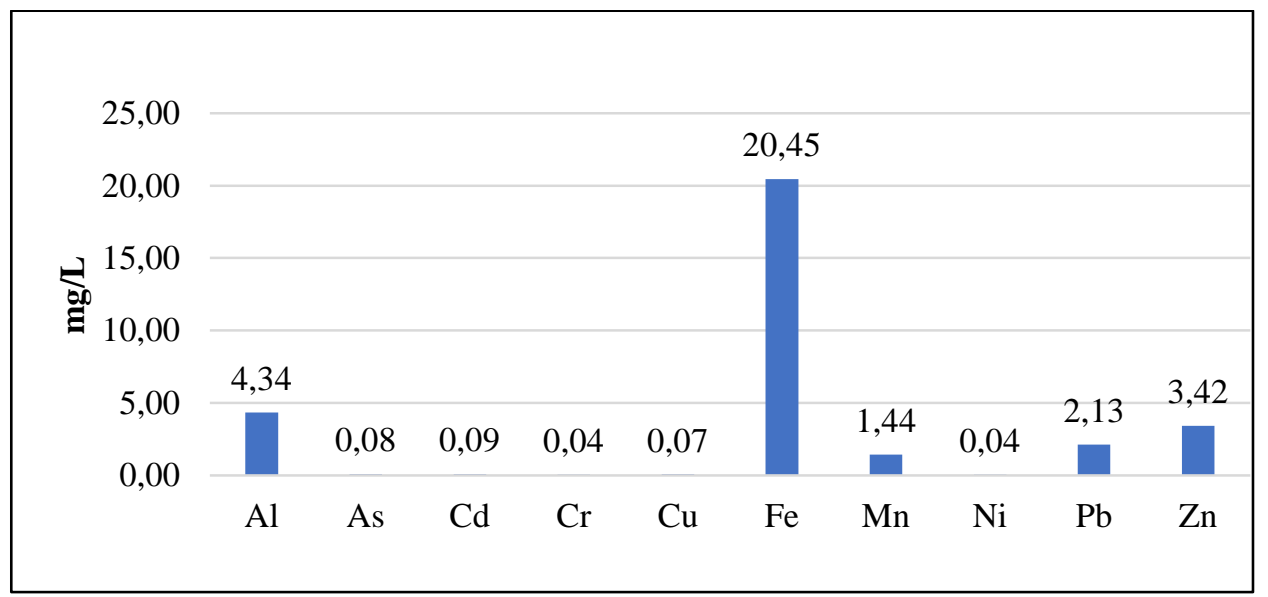

Şekil 3. Su ve kohezyon suyu numunelerinin ortalama metal içerikleri 
Çizelge 7. 1993 WHO, 1998 AB, 2005 TSE 266 Standartları karșılaștırılması

\begin{tabular}{|l|c|c|c|c|}
\hline Metal & Birim & WHO & AB & TSE \\
\hline Antimon & $\mu \mathrm{g} / \mathrm{L}$ & 5 & 5 & 5 \\
\hline Arsenik & $\mu \mathrm{g} / \mathrm{L}$ & 10 & 10 & 10 \\
\hline Benzen & $\mu \mathrm{g} / \mathrm{L}$ & - & 1 & 1 \\
\hline Bor & $\mu \mathrm{g} / \mathrm{L}$ & 0,3 & 1 & 1 \\
\hline Bromat & $\mu \mathrm{g} / \mathrm{L}$ & - & 10 & 10 \\
\hline Kadmiyum & $\mu \mathrm{g} / \mathrm{L}$ & 3 & 5 & 5 \\
\hline Krom & $\mu \mathrm{g} / \mathrm{L}$ & 50 & 50 & 50 \\
\hline Bakır & $\mu \mathrm{g} / \mathrm{L}$ & 2000 & 2000 & 2000 \\
\hline Siyanür & $\mu \mathrm{g} / \mathrm{L}$ & 70 & 50 & 50 \\
\hline Florür & $\mu \mathrm{g} / \mathrm{L}$ & 1,5 & 1,5 & 1,5 \\
\hline Kurşun & $\mu \mathrm{g} / \mathrm{L}$ & 10 & 10 & 10 \\
\hline Civa & $\mu \mathrm{g} / \mathrm{L}$ & 1 & 1 & 1 \\
\hline Nikel & $\mu \mathrm{g} / \mathrm{L}$ & 20 & 20 & 20 \\
\hline Nitrat & $\mu \mathrm{g} / \mathrm{L}$ & 50 & 50 & 50 \\
\hline
\end{tabular}

Maden civarından toplanan toprak ve sediment numuneleri incelendiği zaman bazı numunelerde US EPA sediment kirlilik sinıflandırmasında ve Toprak Kirliliği Kontrolü Yönetmeliği'nde belirtilen topraktaki ağır metal sınır değerlerine göre yüksek konsantrasyonlarda), çinko (2.180- $45.040 \mathrm{mg} / \mathrm{kg})$, bakır $(90-2.600 \mathrm{mg} / \mathrm{kg})$, kadmiyum (1,4-193 $\mathrm{mg} / \mathrm{kg}), \quad$ kurşun $(32-79.670 \mathrm{mg} / \mathrm{kg}$ ) mevcut olduğu belirlenmiştir.

Şekil 3 incelendiğinde ortamdan alınan su numunelerinde $\mathrm{Fe}, \mathrm{Zn}, \mathrm{Pb}$ ve $\mathrm{Al}$ içerikleri göze çarparken; kohezyon su numunelerinde özellikle Mn içeriği dikkat çekmektedir.

Araştırma bölgesinden alınan toprak ve sediment numunelerinin $\mathrm{Al}, \mathrm{As}, \mathrm{Cd}, \mathrm{Cr}, \mathrm{Cu}, \mathrm{Fe}, \mathrm{Ni}, \mathrm{Mn}, \mathrm{Pb}$ ve $\mathrm{Zn}$ içerikleri sırasıyla 6,$72 ; 0,63 ; 0,04 ; 0,03$; 0,$42 ; 131,6 ; 0,03 ; 0,84 ; 8,55$ ve $11,52 \mathrm{~g} / \mathrm{kg}$ 'dır. Su ve kohezyon suyu numuneleri ağır metal konsantrasyonları ise sirasiyla 4,34; 0,$08 ; 0,09$; 0,$04 ; \quad 0,07 ; \quad 20,45 ; \quad 0,04 ; \quad 1,44 ; \quad 2,13$ ve $3,42 \mathrm{mg} / \mathrm{lt}^{\prime}$ dir.
Söz konusu çalışma alanındaki maden drenaj atıkları yerleştirilirken ve yerleştirildikten sonra üzerlerine kireç eklenmesi ile ortam $\mathrm{pH} 1$ nötral düzeylere yükseltilmekte dolayısıyla ağır metallerin ortamda çökelmiş veya adsorblanmış halde bulunması ve suya karışmaması sağlanmaktadır [21,22].

Alınan toprak ve sediment numunelerinde tespit edilen arsenik konsantrasyonları, maden atıklarında yüksek miktarda arsenik bulunduğunu zaten ortaya koymaktadır. Ancak atıklara kireç eklenmesi ile $\mathrm{pH}$ 'ın nötral düzeyde tutulması ve dolayısıyla oluşan demir hidroksit ve mangan oksit (minerallerinin arseniği adsorplanmış halde bulunduracağ1 düşünüldüğünden, maden atık drenaj1 kohezyon suyunda ölçülen bu arsenik değeri ortamda farklı bir jeokimyasal aktivitenin gerçekleştiğini ortaya koymaktadır. Arseniğin suda çözünmesi ancak bu demir hidroksit ve/veya mangan oksitlerin çözünmesi ile gerçekleşebilir. Kohezyon suyu demir konsantrasyonlarına baktığımız zaman $71,87 \mathrm{mg} / \mathrm{L}$ görülmektedir. $\mathrm{Bu}$ değer yine maden atık kümesi drenaj suyundaki demir $(7,12 \mathrm{mg} / \mathrm{L})$ değerleri ile karşılaştırıldığında yaklaşık on katı bir değere sahiptir. Bu değerler, sediment kohezyon sularındaki demir (hidr)oksitlerin bir jeokimyasal değişiklik sonucu çözünüp suya karıştığını göstermektedir. Nitekim, maden atık kümesinde ölçülen demir konsantrasyonları da, bu elementlerin oksitlerinin çözünmekte olduğunu doğrulamaktadır. Maden atık kümesi drenaj kanalında yoğun miktarda yaprak ve bitki kalıntıları gözlemlenmiş ve bu kalıntıların çürümesi dolayısıyla sedimentlerdeki organik karbon miktarının yükseldiği ve bir indirgeyici ortam oluştuğu düşünülmektedir. Demir ve mangan oksitlerin bu koşullarda indirgenmesi ve çözünmesi dolayısıyla arseniğin de suya, kohezyon suyuna karışması muhtemeldir.

Adana'nın Horzum Yaylası civarında bulunan işletimi durmuş bir çinko-kurşun madeni, maden drenaj ve maden atık kümesi drenaj bölgesinden alınan toprak, su, sediment ve bitki toprağı numunelerinde yapılan ağır metal ve arsenik analizleri sonucuna göre gerek maden drenaj suyu ve gerekse maden atık kümesi drenaj suyunda alıcı ortamlara ulaşacak yükseklikte bir kirlilik yüküne 
rastlanmamıştır. Maden atık kümesi üzerine eklenen kireç ilavesi ile $\mathrm{pH}$ yükseltilerek metallerin hidroksit formunda çöktürülmesi veya çöken metal hidroksitlerin üzerine adsorplanması sağlanmıştır.

\section{KAYNAKLAR}

1. MTA, Adana İli Maden ve Enerji Kaynakları, 2001.

2. Gutierrez M., Mickus K., 2016. Abondened $\mathrm{Pb}-\mathrm{Zn}$ Mine Mining Wastes and Their Mobility As Proxy to Toxicity : A Review, Science of the Total Environment 565, 392-400.

3. Kusin, F.M., Jarvis, A.P., Gandy, C.J., 2012. Hydraulic Performance Assessment of Passive Coal Mine Water Treatment Systems in the UK, Ecological Engineering; 49: 233-243.

4. Kusin, F.M., Jarvis, A.P., Gandy, C.J., 2014. Hydraulic Performance and Iron Removal in Wetlands and Lagoons Treating Ferruginous Coal Mine Waters, Wetlands; 34: 555-564.

5. Benvenuti, M., Mascaro, I., Lattanzi, P., Parrini P., Tanelli, G., 1997. Mine Waste Dumps and Heavy Metal Pollution in Abandoned Mining District of Boccheggiano Southern Tuscany, Italy, Environmental Geology, 30: 238-24.

6. Wang, S., Mulligan, C.N., 2005. Occurrence of Arsenic contamination in Canada: Sources Behavior and Distribution. Science of the total Environment, 366: 701-721.

7. Navorro, M.C., Perez-Sirvent, C., MartinezSainchez, M.J ., 2007. Abandoned Mine Sites as a Source of Contamination by Heavy Metals: A Casestudy in a Semi-Arid Zone. Journal of Geochemical Exploration, 96: 183-193.

8. Schwab, P., Zhu, D., 2007. Heavy Metal Leaching from Mine Tailings as Affected by Organic Amendments, 98: 2935-2941.

9. Madzin, Z., Shai-In M., Kusin, F., 2015. Comparing Heavy Metal Mobility in Active and Abandoned Mining Sites at Bestari Jaya, Selangor, Procedia Environmental Sciences, 30: 232-237.

10. Widerlung, A., Ingri, J., 1995. Early Diagnosis of Arsenic in Sediments of the Kalix River
Estuary, Northern Sweden, Chemical Geology, Vol. 125, 3-4,185-196.

11. Yan, X.P., Kerrich, R., Hendry, M.J., 2000. Distribution of Arsenic (III), Arsenic (IV) and Total Inorganic Arsenic in Porewaters from a Thck Till and Clay-Rich Aquitard Sequence, Saskatchewan, Canada, Geochimica et Cosmochimica Acta, Vol 62, No 15, 2637-2648.

12. Bech, J., Poschenrieder, C., Llugany, M., Barcelo, J., Tuma, P., Tobias, F.J., Barranzuela, J.L., Vasquez, E.R., 1997. Arsenic and Heavy Metal Contamination of Soil and Vegetation Around a Copper Mine in Northern Peru, The Science of the Total Environment 203, 83-91.

13. Lee, C.G., Chon, H.T., Jung, M.J. 2001. Heavy Metal Contamination in the Vicinity of the Daduk Au-Ag-Pb-Zn Mine in Korea. Applied Geochemistry, 16;1377-1386.

14. Rotkittikhun, P., Kruatrachue, M., Chaiyarat, R., Ngernsansaruay, C., Pokethitiyook, P., Paijitprapaporn, A., Baker, A.J.M., 2006. Uptake and Accumulation of Lead by Plants from the Bo Ngam Lead Mine Area in Thaliand, Environmental Pollution, 144, 681-688.

15. Laghlimi, M., Baghdad, B., 2015. Characterization of Soil Heavy Metal Contamination in the Abandoned Mine of Zaida (High Moulouya, Morocco), International Research Journal of Earth Sciences, Vol 3(3), 1-3.

16. Monterroso, C., Rodriguez, F., 2014. Heavy Metal Distribution in Mine-Soils and Plants Growing in a $\mathrm{Pb} / \mathrm{Zn}$ Mining Area in NW Spain, Applied Geochemistry , 44, 3-11.

17. Liu, Y.G., Zhang, H.Z., Zeng, G.M., Huang, B.R., Li, X., 2006. Heavy Metal Accumulation in Plants on Mn Mine Tailings, Soil Science Society of China, 16(1), 131-136.

18. Environmental Protection Agency (EPA), Method 3051A. 2007. Microwave Assisted Acid Digestion Of Sediments, Sludges, Soils and Oils.

19. Perin, G., Bonardi, M., Fabris, R., Simoncini, B., Manente, S., Tosi, L., Scotto, S., 1997. Heavy Metal Pollution in Central Venice Lagoon Bottom Sediments: Evaluation of 
Metal Bioavailability by Geochemical Speciation Procedure. Environmental Technology 18; 593-604.

20. Çevre ve Orman Bakanlığı. 2005. Toprak Kirliliğinin Kontrolü Yönetmeliği, Resmi Gazete (25831).

21. De Andrade, R.P., Figueiredo, B.R., De Mello, J.W.V., Santos, J.C.Z., Zandonadi, L.U., 2008. Control of Geochemical Mobility of Arsenic by Liming in Materials Subjected to Acid Mine Drainage. Journal of Soils and Sediments. 8, 2; 123-129.

22. Perez-Lopez, R., Quispe, D., Castillo, J., Nieto, J.M., 2011. Acid Neutralization by Dissolution of Alkaline Paper Mill Wastes and Implications for Treatment of Sulfide-Mine Drainage. American Minerologist. 96; 5-6, 781-791. 
